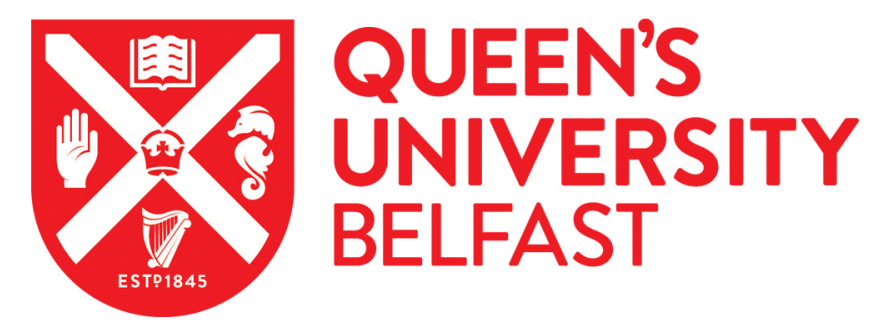

\title{
Wellbeing, academic buoyancy and educational achievement in primary school students
}

Miller, S., Connolly, P., \& Maguire, L. K. (2013). Wellbeing, academic buoyancy and educational achievement in primary school students. International Journal of Educational Research, 62, 239-248.

https://doi.org/10.1016/j.ijer.2013.05.004

Published in:

International Journal of Educational Research

Document Version:

Early version, also known as pre-print

Queen's University Belfast - Research Portal:

Link to publication record in Queen's University Belfast Research Portal

Publisher rights

Copyright $\odot 2013$ Elsevier Ltd.

This is an open access article published under a Creative Commons Attribution-NonCommercial-NoDerivs License

(https://creativecommons.org/licenses/by-nc-nd/4.0/), which permits distribution and reproduction for non-commercial purposes, provided the author and source are cited.

\section{General rights}

Copyright for the publications made accessible via the Queen's University Belfast Research Portal is retained by the author(s) and / or other copyright owners and it is a condition of accessing these publications that users recognise and abide by the legal requirements associated with these rights.

Take down policy

The Research Portal is Queen's institutional repository that provides access to Queen's research output. Every effort has been made to ensure that content in the Research Portal does not infringe any person's rights, or applicable UK laws. If you discover content in the Research Portal that you believe breaches copyright or violates any law, please contact openaccess@qub.ac.uk. 
Wellbeing, academic buoyancy and educational achievement in primary school students

Sarah Miller ${ }^{\mathrm{a}}$, Paul Connolly ${ }^{\mathrm{a}}$ and Lisa K. Maguire ${ }^{\mathrm{a} 1}$

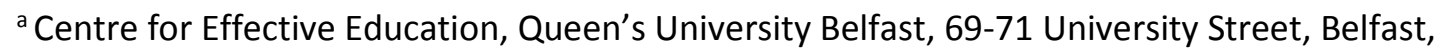
BT7 1HL, Northern Ireland.

Corresponding author: Dr Sarah Miller, email: s.j.miller@qub.ac.uk, tel: +44(0)28 90975944, fax: $+44(0) 2890975066$.

Word count: 7,974 (including references and tables)

\footnotetext{
${ }^{1}$ Present address: All-Ireland Hub for Trials Methodology Research, Centre for Public Health Queen's University Belfast, Institute of Clinical Science, Block B, Grosvenor Road, Belfast, BT12 6BJ
} 


\title{
Wellbeing, academic buoyancy and educational achievement in primary school students
}

\section{Highlights}

Research explored wellbeing and academic achievement in 1081, 7-11 year-old students. Data indicated the existence of a general wellbeing factor in students.

Wellbeing was significantly, positively related to academic achievement in students.

Academic buoyancy provides a frame to understand the relationship between wellbeing and achievement.

\begin{abstract}
The study explored the relationship between student wellbeing and academic achievement among 7-11 year-old students and whether the relationship was moderated by gender and deprivation. 1,081 students in Northern Ireland participated in a cross-sectional survey that captured data on academic achievement and a range of wellbeing indicators. Findings suggested the existence of an underlying wellbeing factor, which was positively related to achievement. The relationship was not moderated by gender and/or deprivation. Findings were explored using a model of 'academic buoyancy'. There was no evidence that suggested efforts to improve achievement that focus on wellbeing should be targeted specifically at students in economically deprived areas or be modified in terms of gender.
\end{abstract}

Key words: wellbeing; educational achievement, academic buoyancy; deprivation; gender. 


\section{Introduction}

This paper reports the findings from a large scale cross sectional survey that examined the relationship between student wellbeing and educational achievement in a sample of 7 to 11 year old primary school students. The paper begins with an overview of the student wellbeing literature and a discussion of some of the limitations of the current conceptualisations of wellbeing. Despite the wealth of research surrounding student wellbeing, it remains a complex and multi-dimensional concept with no universally accepted definition (Coleman, 2009; Camfield, Streuli, \& Woodhead, 2009; Columbo, 1986; Gutman, \& Levy, 1982). Much of the research in the area is empirical and lacking a theoretical framework by which to fully understand the role of student wellbeing in relation to improving academic outcomes. With this in mind, and in the context of the findings presented from this study, the notion of academic buoyancy (Martin \& Marsh, 2006; 2008) is suggested as a useful way to better understand and conceptualise the wellbeing of students in an educational context. Findings from the current study are located within a framework of academic buoyancy and data are used to confirm and extend the theory insofar as it relates to academic achievement, as well as explore whether wellbeing is moderated by gender and socioeconomic deprivation.

\section{Wellbeing and educational achievement}

Over recent years there has been increasing interest in the notion of wellbeing and how this relates to positive outcomes in education. Wellbeing is a general term related to the social and emotional heath and development of students. It has become the main social-construct by which teachers, psychologists, counsellors, parents and researchers measure and compare the affective development of students. However, research in the last decade has reported inconsistent relationships between various aspects of wellbeing and academic achievement (e.g. Heckman, Stixrud \& Urzua, 2006; Berger, Alcalay, Torretti \& Milicic, 2011; Suldo \& Shaffer, 2008; Saab \& Klinger, 2010; Nicholson, Lucas, Berthelsen \& Wake, 2012). Heckman et al. (2006), for example, used data from the 1979 National Longitudinal Survey of Youth (participants aged 14 to 22 years-old) to demonstrate that non-cognitive traits, in this case self esteem (Rosenberg, 1965) and locus of control (Rotter, 1966), can be a more powerful predictor of school and life success than cognitive traits such as IQ. Similarly, a cross-sectional survey of 674 Chilean students aged nine to 11 years-old found that self esteem predicted academic achievement (grade average). It was also reported that 
wellbeing measured by a 52 item Chilean wellbeing scale (Arab, 2009), social integration, classroom social climate and peer social networks were not predictors of academic achievement (Berger, et al., 2011). In a sample of 349 ten to 16 year olds Suldo and Shaffer (2008) measured wellbeing using the Students' Life Satisfaction Scale (Huebner, 1991) and the Positive and Negative Affect Scale for Children (Laurent et al., 1999). Interestingly they reported that wellbeing alone was not a sufficient condition for academic success (measured by grade point average and standardised test scores) but instead needed to be present together with low psychopathology to facilitate better academic functioning. Furthermore, in a randomised controlled trial of peer tutoring involving $168,10-11$ year-old students, it was noted that improvements in self esteem (Rosenberg, 1965) were driven upwards by enhancements in belief and confidence (Miller, Topping \& Thurston, 2010).

In addition to the evidence suggesting that wellbeing is related to academic achievement, there is also evidence to suggest that students from areas of disadvantage report poorer wellbeing outcomes (as well as poorer educational outcomes) than their more affluent peers. As Nicholson et al. (2012) observe: 'Exposure to socioeconomic disadvantage in childhood impairs student's wellbeing with adverse effects persisting into adulthood' (p.81). Saab and Klinger (2010) measured wellbeing using an un-validated Canada-specific scale in a sample of 6,126 students aged 11 to 16 from 134 schools. They found that greater family wealth and better wellbeing were both significantly associated with academic achievement, although no details of the measure used for academic achievement were provided.

Similar relationships have also been reported for younger students. Nicholson et al. (2012) used data from the Longitudinal Study of Australian Children (LSAC) $(n=5,000)$ to show that socio-economic disadvantage was significantly associated with poorer wellbeing outcomes in a sample of 4-5 year-old students. Data were captured by a variety of measures including the Brief Infant Toddler Social and Emotional Assessment Competence Scale and the Strengths and Difficulties Questionnaire. Data indicated poorer vocabulary and emergent literacy skills (measured using standardised tests including the Peabody Picture Vocabulary Scale, PPVT III) in students from lower socio-economical homes. This effect was most marked for the older students in the sample. While Farmer and Hanratty (2012) did not look at educational achievement they did explore the relationship between wellbeing, low income and substance use. Wellbeing was measured using the UK national indicator questions: 'Has one or more good friends'; 'I can talk to my parents; 'I can talk to my 
friends'; 'I can talk to an adult who is not my parent'; as well as the question 'I feel happy about life'. The sample included 3,903 students aged between ten and 15 years and the authors reported that students who were eligible for free school meals (FSM) - a proxy for low income and approximately $20 \%$ of the sample - were more likely to report that they were unhappy compared to students who were not eligible for FSM (33.2\% compared with 27.2\%). Furthermore, students who reported feeling happy were one-third less likely to report having tried smoking, using alcohol or drugs than those who were less happy. However, the low number of scaled items and the large variance in sub-sample size make definitive conclusions problematic.

This relationship between wellbeing, deprivation and achievement has led to an emphasis within some educational intervention programmes on building particular aspects of wellbeing among students, such as social emotional skills and prosocial behaviour, as a means of improving educational outcomes. Durlak et al.'s (2011) meta-analysis of 213 school-based social and emotional learning programmes suggests that such interventions improve academic achievement (as measured by standardised test scores and grade point averages) by a mean effect size of 0.27 . Only a subset of the 213 studies measured achievement and were included in this analysis, nevertheless the pooled sample size was large $(n=135,396)$. However, it is not clear from the review which of the 213 studies measured academic achievement and what the characteristics of the interventions were that contributed to improvements in this particular outcome.

The evidence that such programmes also improve academic outcomes may be more equivocal than is suggested by Durlak and colleagues. For example, Positive Action is a programme which aims to promote social emotional skills, character development, academic achievement and to reduce problem behaviour. Flay, Acock, Vuchinich and Beets (2006) evaluated this programme using a randomised controlled trial (RCT) design involving 20 schools and 2,666 students aged nine to 11 years. The authors reported that in addition to improved behavioural outcomes (including reduced suspension rates, use of alcohol, tobacco and drugs) the intervention group also demonstrated improved grade retention rates compared to the control group, however there was no measureable impact on state standardised test scores of academic achievement. 
Similarly, the Caring School Community programme (formerly the Child Development Project) aims to improve core values, prosocial behaviour and a feeling of community within the school for students aged five to 12 years. An RCT evaluation involving over 600 students in six schools demonstrated that students who took part in the programme reported improved prosocial behaviour however there were no measurable benefits of the programme in academic achievement, as measured by standardised tests (Battistich, 2003). Conversely however the findings from evaluations of a programme called Early Risers indicated that it did improve achievement for participating students. Early Riser is aimed at students aged five to 11 years whose behaviour is starting to become aggressive and disruptive. Students are taught skills that promote emotional and behavioural self-regulation, positive peer relationships and academic success. Two randomised controlled trials, involving 389 students and 30 schools, have demonstrated that the programme had no measurable impact on behavioural outcomes however it did improve social skills and academic achievement, as measured by the Woodcock Johnson Tests of Achievement Revised (August et al., 2002; August et al., 2003).

\subsection{Defining and measuring student wellbeing}

As outlined above, while there is now a growing body of research that has explored the relationship between wellbeing and educational outcomes, there remains the issue of how wellbeing is to be defined and understood. Since the 1960s psychologists have moved from a deficit model of wellbeing (Nettle, 2005) to one that views wellbeing as more than simply the absence of problems and that includes a range of positive feelings (Bowling, 2005; Sin, \& Lyubomirsky, 2009, Diener, 1994) and the opportunity to live a 'flourishing life' through relationships with self, others and the environment (Gill, 2009). However, wellbeing continues to be variably and inconsistently defined, operationalized and studied which, unsurprisingly, has led to a research base that is diverse and at times unclear and discrepant (Morrow, \& Mayall, 2009; Crivello, Camfield, \& Woodhead, 2009; Coleman, 2009; Camfield, Streuli, \& Woodhead, 2009; Pollard, \& Lee, 2003).

In its broadest sense wellbeing can include physical, material and educational dimensions as well as the more familiar social and emotional elements of the construct. Given the lack of consensus regarding the definition, it follows that this has also had implications for the measurement of wellbeing, not least because of its multi-dimensional nature. Suldo and Shaffer (2008) defined wellbeing as the scientific term for happiness and a positive indicator 
of mental health. Other studies (e.g. Berger et al., 2011; Saab \& Klinger, 2010; Gutman \& Feinstein, 2008) have used single measures of wellbeing, that are sometimes un-validated and country-specific, alongside a range of other measures/dimensions of wellbeing such as self esteem and peer relationships, without providing an explicit definition of wellbeing per se.

The studies outlined above demonstrate an often inconsistent relationship between wellbeing and achievement and it is clear that the research to date has tended to look at different indicators of wellbeing and their relationship with achievement. This, in turn, has highlighted the fact that while a great deal of the research in this area has been empirical, much of it has lacked any theoretical underpinning. This is evident, for example, in the study by Farmer and Hanratty (2012) discussed earlier that found that a relationship between wellbeing and deprivation but did not attempt to explain why or how this relationship might operate. In a similar vein Berger et al. (2011) and Nicholson et al. (2012) who also explored the relationship between wellbeing, achievement and deprivation focused on the empirical contribution of their work but did not attempt to apply their findings to any theoretical framework or conceptualisation of wellbeing.

Heckman et al. (2006) suggest the reason that early childhood programmes such as Headstart are effective in improving academic, social and economic outcomes is not because such programmes improve IQ but because they improve non-cognitive skills. Similarly DiPerna and Elliott (2002) identify academic enablers within student behaviours, which are non-academic, and that, in combination with academic skill, result in academic success. They define academic enablers as 'the non academic skills, attitudes and behaviours that allow a student to participate in and ultimately benefit from academic instruction in the classroom' (p. 294).

More specifically it is thought that socio-emotional learning (Lopes \& Salovey, 2004) might improve academic achievement by improving emotional regulation skills such as the ability to attend, concentrate and engage with work and ability to moderate and self-regulate impulses and behaviours in social contexts. It follows that this would enable the student to 'sit still' through class during teaching and better concentrate and attend to their work. This ultimately fosters 'sustained intellectual engagement and studying' (Lopes \& Salovey, 2004, p79) and is consistent with findings from studies that have specifically looked at the role of 
self-discipline and control in relation to academic achievement and found it to be a powerful and robust predictor of achievement (Duckworth \& Seligman, 2005; Wolfe \& Johnson, 1995).

The differing aspects that have been reported to constitute wellbeing have also been synthesised into a framework that articulates them together through the notion of 'academic buoyancy' (Martin \& Marsh, 2008; 2009). This approach combines psychological factors (self-esteem and psychological health); school engagement factors (school environment and enjoyment of education); and family and peer relationship factors (parent relations and peer relationships) to provide a combined view of wellbeing that is described as academic buoyancy. The model attempts to explain how these factors may interplay and manifest themselves in relation to a school setting and academic achievement. Students with high levels of academic buoyancy are thought to be better able to weather the day-today challenges of school life, thus it acts as a protective factor and serves to 'activate composure' (Martin \& March, 2008: p74). Similarly, persistence, control and engagement have all been shown to be positively and significantly correlated with academic buoyancy (ibid) and this may well be the pathway through which academic buoyancy contributes to improved achievement. This has not as yet been tested however and to date, the work in this area has largely been concerned with the psychometric properties of the notion rather than further exploring its relationship with achievement. Moreover, existing work has tended to focus on exploring academic buoyancy using specific school-related measures rather than a more general indicator of wellbeing.

Other attempts have been made to unify the various perspectives in relation to the study of wellbeing (Ryff, \& Keyes, 1995; Huppert, \& Baylis, 2004) but not around educational outcomes, despite the UK government's increasing emphasis on promoting wellbeing for students and young people in the school setting (for example, DCFS, 2007; Connolly, Sibbett, Hanratty, Kerr, O'Hare, Winter, 2011). It is with this in mind that this study seeks to explore a range of indicators of wellbeing, how they relate together and what association, if any, they have to academic achievement in school. The methodological approach adopted by the study, including the different indicators of wellbeing selected, is set out in the following section.

\section{Methodology}


In an attempt to study the relationship between wellbeing, deprivation and achievement this study used a cross sectional survey design and data were collected between March and May 2008. Ethical approval for the study was granted by the Research Ethics Committee of the School of Education at Queen's University Belfast. Both parent and student consent were obtained prior to data collection.

\subsection{Measures}

Given the lack of clarity regarding wellbeing and how to define and measure it the present study used six of the most common measures of wellbeing that broadly cover the three key proximal dimensions of academic buoyancy identified by Martin and Marsh (2008; 2009) which include psychological factors; school engagement factors, and; family and peer relationship factors. Details of the measures that were used are described below and summarised in Table 1.

\section{[TABLE 1 ABOUT HERE]}

Psychological health was measured using KIDSCREEN, which is an instrument that measures perceived health and health related quality of life of younger students and adolescents (The Kidscreen Group Europe, 2006). In total, this study used five subscales from the KIDSCREEN measure, the first of which was Psychological Health, which examined the wellbeing of the student including positive emotions and satisfaction with life. High scores indicate happiness and that the respondent is emotionally balanced and satisfied with life. The Global Self Worth subscale of the Self Perception Profile for Children (SPPC) (Harter, 1985) was used to measure self-esteem.

To measure school engagement two measures were used. Firstly, the School Environment subscale of KIDSCREEN explores the student's perception of his/her learning and concentration at school. High scores on this scale indicate feeling happy at school and doing well. Secondly, the 'liking school' subscale of Pell and Jarvis's (2001) attitudinal scale was used as a measure of enjoyment of school.

Parent relations were assessed through the Autonomy and Parent Relations subscale of KIDSCREEN which explores the relationship between the student and their parents. It also explores the perceived level of autonomy to create social and leisure time. Similarly, peer 
relationships were measured using the Peer Relationships subscale of KIDSCREEN, which examines the nature of social relationships. High scores on this scale indicate feeling accepted, supported and included.

Educational achievement was measured using students' most recent level of achievement in their English and Math Key Stage teacher assessments. Students are not required to sit formal tests at the end of Key Stages 1 and 2 in Northern Ireland and so Key Stage teacher assessments were the only available data on educational achievement. It is acknowledged that this is a relatively basic measure of achievement and has limited psychometric quality. Although there is debate in relation to the reliability of teacher assessments versus external tests, teacher assessments remain an important and valid source of data that count in terms of students' outcomes and life chances (Harlen, 2004). Key Stage data were collected directly from the school. Key Stage levels and standards are developmental in nature and not age standardised. Students in Year 4, age 7-8 years, are assessed on Key Stage 1 standards and are classified at the following levels: W (working towards level 1); Level 1 (below nationally expected standard); Level 2 (nationally expected standard); Level 3 (above nationally expected standard); or Level 4 (exceptional performance). Year 7 students, age 10-11 years, were assessed on Key Stage 2 standards and can achieve: Level 1 (below nationally expected standard); Level 2 (below nationally expected standard); Level 3 (below nationally expected standard); Level 4 (nationally expected standard); Level 5 (above nationally expected standard); and Level 6 (exceptional performance).

Data on age, gender, ethnicity and postcode were also collected. The Noble Northern Ireland Multiple Deprivation Measure (Northern Ireland Statistics and Research Agency, 2005) is a measure of spatial deprivation and was used as a proxy for socio-economic status. It comprises seven domains: deprivation; income; employment; health; education; proximity to services; living environment; and crime. Northern Ireland is divided into 890 super output areas, equivalent to electoral wards or subdivisions of electoral wards, which are ranked according to their level of deprivation, from 1 (most deprived) to 890 (least deprived). Postcodes were used in this study to determine each participant's super output area and thus the deprivation ranking of that local area.

\subsection{Procedure}


A questionnaire, containing the measures of wellbeing described above, was administered to each participating student in a classroom setting. Students were consulted during the design and pilot phase of the questionnaire and this is reported in more detail elsewhere (Lundy \& McEvoy, 2009). A trained fieldworker read each question aloud while the students recorded their answers in a questionnaire booklet. The measures were piloted with 60 Year 4 and Year 7 students prior to administration to test their feasibility.

\subsection{Sample}

Initially, 82 primary schools were randomly selected from a list of all primary schools in Northern Ireland, stratified by Education and Library Board area, with over-sampling of high deprivation schools. Twenty-eight of the 82 schools (34\%) invited to take part agreed to participate. All students at the end of Key Stage 1 (aged 7-8 years old) and the end of Key Stage 2 (aged 10-11 years old) in participating schools were invited to take part in the survey resulting in a sample of 1,081 students.

\section{Findings}

\subsection{Participants}

A total of 1,081 students from the 28 primary schools across Northern Ireland took part in the study, $47.2 \%$ were girls $(n=510)$ and $52.8 \%$ were boys $(n=571)$. The mean age of the sample was 9.34 years-old (SD 1.55 years). The ethnic background of the sample was overwhelmingly white with nearly all respondents describing themselves as Caucasian Northern Irish, Irish or British (99.1\%). Table 2 describes the sample characteristics by gender and year group.

\section{[TABLE 2 ABOUT HERE]}

Fifteen of the 28 schools were located in areas of high deprivation and $25 \%$ of the students in the sample lived in areas ranked 49 or lower (out of 890 ) on the multiple deprivation index, where 1 is most deprived and 890 is least deprived. The mean multiple deprivation ranking was 214.49 (SD 155.21) and no student lived in an area ranked higher than 470. Five per cent of students $(n=57)$ did not give their consent for their answers to be included in the study.

\subsection{Educational achievement}


Data on educational achievement were only available for 695 of the 1,081 students in the sample (64\%). Table 3 shows the number of students in the sample achieving each level of the Key Stage standards in both English and Math. It is evident from Table 3 that the achievement levels of the sample are somewhat lower than the overall achievement levels across Northern Ireland in the same year (2007/8) (Council for the Curriculum Examinations and Assessment, 2008). This may be a consequence of the sample being selected from areas of higher deprivation and thus the sample isn't necessarily representative of the population as a whole.

\section{[TABLE 3 ABOUT HERE]}

To obtain a composite 'achievement' score the Key Stage levels attained for both English and Math were added together for each student so that achievement scores could range potentially between 2 and 12, see Table 4 . This was a valid approach to creating an overall achievement score as there was a strong, positive correlation between English and Math scores $(r=0.97, p<0.001)$. This means that Year 4 students who are achieving the nationally expected standard or above in both English and Math at Key Stage 1 (i.e. Level 2 and above) will have a composite score of 4 or higher. A score of 3 or lower indicates that these Year 4 students are achieving below the national expected standard in Key Stage 1 for English, Math or both. Year 7 students who are achieving the nationally expected standard or above in both English and Math at Key Stage 2 (i.e. Level 4 and above) will have a composite score of 8 or higher. A score of 7 or lower indicates that these Year 7 students are achieving below the national expected standard in Key Stage 2 for English, Math or both.

\section{[TABLE 4 ABOUT HERE]}

\subsection{Wellbeing}

The data from the current study appear to support the existence of a single underlying wellbeing factor. Firstly, the six measures of wellbeing described in Section 3.1 were found to combine to produce an internally reliable scale (Cronbach's alpha coefficient $=0.75$ ). Secondly, an unrotated principal factors analysis $(n=1072)$ showed that the measures also formed a valid, single item scale as detailed in Table 5. The Kaiser-Meyer Olkin measure of sampling adequacy indicated that the sample was factorable $(\mathrm{KMO}=0.76)$. Given this, a single wellbeing score was derived by calculating the mean score across all six measures of 
wellbeing. This score comprised 37 items (Cronbach's Alpha $=0.75$ ) and a range within the sample of 1.96 to 4.83 with a mean of $3.95(s d=0.49)$.

\section{[TABLE 5 ABOUT HERE]}

\subsection{Wellbeing and gender and deprivation}

Prior to the main analysis below, the relationship between wellbeing and gender and wellbeing and deprivation was explored using two simple linear regressions, employing robust standard errors to take account of the clustering of the students within schools. This analysis found that neither gender nor deprivation predicted wellbeing at the 0.05 level of significance, however the level of significance was less than 0.1 in both cases, with girls reporting higher levels of wellbeing than boys and students from more deprived backgrounds reporting higher levels of wellbeing compared to students from less deprived backgrounds. See Table 6 for the parameter estimates of these two simple models.

\section{[TABLE 6 ABOUT HERE]}

\subsection{Wellbeing and educational achievement}

The primary aim of the following analysis was to test the relationship between wellbeing and educational achievement and to explore whether this relationship is moderated by gender and deprivation. Since the response variable (overall academic achievement) is an ordinal variable, ordered logistic regression models were fitted with robust standard errors to take account of the clustered nature of the data. The models were run in four stages described below and the analysis was conducted using Stata 12.

The first ordinal logistic regression model included only wellbeing as the predictor variable whilst controlling for year group (given that the academic achievement variable is not standardised with respect to age). It can be seen from Table 7 that greater wellbeing is associated with higher achievement in school. The overall goodness of fit test indicated that the full model was a significantly better 'predictor' of academic achievement than the intercept only (baseline) model with McFadden's $R^{2}=23.4 \%$ (McFadden's $R^{2}$ compares the likelihood for the intercept only model to the likelihood for the full model). The second model included gender and deprivation as predictor variables in addition to wellbeing and year group. It appears that greater wellbeing and lower levels of deprivation are associated 
with better academic achievement whilst gender is not associated with achievement once wellbeing is controlled for.

The final two models explored the moderating influence of gender and deprivation on the relationship between wellbeing and achievement. Thus, the third model included an interaction term between wellbeing and gender while the fourth model included an interaction term between wellbeing and deprivation. It can be seen from Table 7 that there are no significant interaction effects between either wellbeing and gender or wellbeing and deprivation. This suggests that the relationship between wellbeing and achievement is robust and applies equally across gender and deprivation.

\section{[INSERT TABLE 7 ABOUT HERE]}

To help interpret Model 2 and the finding of a statistically significant relationship between wellbeing, deprivation and educational achievement, the predicted probabilities of attaining the expected national standard in terms of overall achievement were calculated for Year 7 (Key Stage 2). High and low levels of wellbeing were calculated as one standard deviation above and below the sample mean. An overall achievement score of eight or higher indicates that students are achieving the expected national standard (or above) in English and Math at Key Stage 2. Using these values and the relevant parameters and cut points (thresholds) ${ }^{2}$ from the model, the regression equation was calculated to model out the relationship and to explore how it was impacting on predicted achievement. It was found that Year 7 students who have high levels of wellbeing do better academically than students with low levels of wellbeing, as the predicted probability of achieving the expected national standard in English and Maths rises from $66.7 \%$ for students with low wellbeing to $76.1 \%$ for students with high wellbeing, an increase of 9.4 percentage points.

\section{Discussion}

The data from the six indicators of wellbeing support the existence of an underlying wellbeing factor, producing a valid and internally reliable scale. Ordinal logistic regression analysis was used to explore whether this measure of wellbeing would predict academic achievement and whether this relationship was moderated by gender and/or deprivation.

\footnotetext{
${ }^{2}$ The $6^{\text {th }}$ cut point (6.501) was used in the equation to calculate the predicted probability of achieving a score of 8 or higher on overall achievement.
} 
The analysis found that there was a statistically significant relationship between wellbeing and academic achievement scores and that this relationship was robust and applied equally across gender and deprivation.

There are three key points to draw out from the findings of this present study. Firstly, it does appear that all of the different indicators of wellbeing used are measuring the same underlying construct. Evidence for this came from the factor analysis and subsequent finding that the sub-scales acted as a single overall wellbeing scale. Thus, and in terms of our first concern, our findings would appear to suggest that it is meaningful to talk about a general sense of wellbeing rather than needing to distinguish between different types. To understand what this general sense of wellbeing is, it is useful to turn to the work of Martin and Marsh and their notion of academic buoyancy (Martin \& Marsh, 2006; 2008). The notion of academic buoyancy originally emerged from the academic resiliency literature; however, the authors maintain that academic buoyancy is distinct from related constructs such as resilience, everyday hassles or coping. Instead they claim buoyancy is more closely aligned to the notion of everyday resilience and focuses on an individual's response to the everyday challenges that are encountered by many people rather than more serious and on-going adversities that are encountered by relatively fewer people (Martin \& Marsh, 2008; 2009). Martin and Marsh define academic buoyancy as: 'students' ability to successfully deal with academic setbacks and challenges that are typical of the ordinary course of school life (e.g. poor grades, competing deadlines, exam pressure, difficult schoolwork)' (Martin \& Marsh, 2008, p54). Government policies on testing regimes, schools, teachers and events in the school life of a student can control the nature and timing of these setbacks. The subsequent effects of the setbacks are mediated by teachers, other staff in schools, parents, peers and through self-regulation and adaptation to these setbacks (buoyancy). In this manner buoyancy can be developed and mediated by external cultural and social resources and by self-regulation of setbacks. Similar findings have been reported in the counselling/psychotherapy literature (Thurston, McLeod \& Thurston, 2012).

Academic buoyancy is located within positive psychology's broaden-and-build theory of positive emotions, which considers positive emotions to be an important vehicle for psychological growth and improved wellbeing, as well as a desirable end in itself (Fredrickson, 1998; 2001). The broaden-and-build theory proposes that positive emotions 'broaden people's momentary thought-action repertoires and build their enduring personal 
resources' (Fredrickson, 2001, p219). Thus, the concept of, academic buoyancy focuses on the individual's response to, rather than the presence of everyday challenges and emphasises proactive rather than reactive approaches to such challenges (Martin \& Marsh, 2008). It is thought to lie on a continuum and to vary according to individual level, as well as environmental level variables.

As indicated earlier, Martin and Marsh (2008) suggest that there are three categories of wellbeing-related proximal factors that predict academic buoyancy: psychological factors; school and engagement factors; and family and peer factors. In turn, academic buoyancy has been shown to predict other school outcomes including class participation, absenteeism, task completion and positive academic intentions (Martin \& Marsh, 2006; Martin \& Marsh, 2008). Thus, it may be suggested that the underlying measure of wellbeing in the present study could be regarded as representing a more general form of buoyancy. The relationship between the combined wellbeing scales and achievement reported could thus be understood, in line with Martin and Marsh, as providing a sense of 'everyday resilience/academic buoyancy'. Whist 'academic resilience' is a term often used it is proposed that buoyancy represents a better label for the processes by which students respond positively to everyday school related challenges and build on their existing social and emotional/self-regulatory resources to meet present and future challenges.

Secondly, and in addition, while Martin and Marsh demonstrated the relationship between a more specific measure of academic buoyancy and achievement, data from the present study has indicated a wider and more general measure of buoyancy is also related to achievement. This, in turn, points to the importance of building wellbeing more generally as a protective factor in relation to educational outcomes. In this sense, our six indicators provide some indication of the type and range of issues that need to be addressed with students in order to build up this general level of buoyancy.

Thirdly, we have demonstrated that there is little relationship between buoyancy and gender or between buoyancy and deprivation. Indeed, and as regards the latter, of that which exists, it is actually in the other direction to what is conventionally thought i.e. students from more deprived areas are reporting greater buoyancy. Moreover, while buoyancy and deprivation each has an impact on achievement, their influence is independent and there is no interaction between them. In other words, the effects of 
buoyancy are similar across all socio economic groups, and for boys and girls. There are clear implications for this in terms of practice and, in particular, the challenge to existing suggestions described earlier that promoting wellbeing is especially important for students from deprived areas. Neither do our findings suggest the need to target interventions at promoting wellbeing at either boys or girls. In contrast, our findings indicate that there is no evidence to warrant a targeted approach to promoting wellbeing, either in terms of deprivation or gender and that, rather, a more universal approach to promoting wellbeing across the population would be appropriate in order to improve educational achievement.

The work does have some limitations. Scaled items used had low numbers of items, however, the scales selected reported good reliability and validity in previous studies and have been widely used in previous literature to report aspects of wellbeing in students. In addition Cronbach alpha values calculated for each scale used in this study were larger than 0.7 indicating that the scales were performing within acceptable parameters for the sample in this study. The greatest threat to validity is the fact that teacher perceptions of achievement were used. Whilst teachers are used to making professional judgements of the levels that students are working at, the inter-rater reliability of such judgements remains a potential source of error. Having said this it should be noted that previous studies have reported that teacher judgement correlated highly with students' performance in standardised tests (Thurston, Christie, Howe, Tolmie, \& Topping, 2008). Future research should address this issue and look at relationships between aspects of wellbeing and student performance in standardised tests.

\subsection{Conclusions}

These findings suggest that the relationship between buoyancy and achievement is robust and applies equally across different groups of students regardless of age, gender and socioeconomic status. It corroborates the underlying premise of the theory which purports that academic buoyancy is a salient construct for all students in terms of improving their academic achievement, not simply those who are dealing with on-going or acute academic adversity (Martin \& Marsh, 2008). This has important implications for programmes that aim to increase academic achievement and suggests that such interventions should be universal and include a focus on improving the dimensions of wellbeing identified here as the constituents of buoyancy in order to further improve achievement. This supports Martin and Marsh's suggestion that intervention and support should be provided at critical times during 
the academic career and directed towards the proximal and 'leading indicators' of academic buoyancy as these are thought to be more responsive to intervention (Martin \& Marsh, 2008). Thus, the findings from the current study provide a means of further understanding the pathway through which academic achievement might be improved and highlight the importance of promoting wellbeing in an educational or school context to positively impact upon buoyancy and subsequently overall educational achievement. 


\section{References}

August, G. J., Hektner, J. M., Egan, E. A., Realmuto, G. M., \& Bloomquist, M. L. (2002). The Early Risers longitudinal prevention trial: Examination of 3-year outcomes in aggressive children with intent-to-treat and as-intended analyses. Psychology of Addictive Behaviors, 16(4, Suppl), S27-S39.

August, G. J., Lee, S. S., Bloomquist, M. L., Realmuto, G. M., \& Hektner, J. M. (2003). Dissemination of an evidence-based prevention innovation for aggressive children living in culturally diverse, urban neighborhoods: The Early Risers effectiveness study. Prevention Science, 4(4), 271-286.

Arab, M. (2009). Design and construction of a scale of social-emotional learning for children from 8-12 years of basic general education. (Unpublished master's thesis). Pontificia Universidad Catolica de Chile, Santiago.

Battistich, V. (2003). Effects of a school-based program to enhance prosocial development on children's peer relations and social adjustment. Journal of Research in Character Education, 1(1), 1-16.

Berger, C., Alcalay, L., Torretti, A., \& Milicic, N. (2011). Socio-emotional well-being and academic achievement: Evidence from a multilevel approach. Psicologia: Reflexão e Crítica, 24(2), 344-351.

Bowling, A. (2005). Measuring health - A review of quality of life measurement scales. Maidenhead: Open University Press.

Bradshaw, J., \& Richardson, D. (2009). An index of child well-being in Europe. Child Indicators Research, 2, 319-351. DOI: 10.1007/s12187-009-9037-

Camfield, L., Streuli, N., \& Woodhead, M. (2009). Children's well-being in developing countries: A conceptual and methodological review. European Journal of Development Research, 22, 398-416. 
Coleman, J. (2009). Well-being in schools - empirical measure, or politician's dream?. Oxford Review of Education, 35(3), 281-292. DOI:10.1080/03054980902934548

Columbo, S. A. (1986). General well-being in adolescents: its nature and measurement. Dissertation Abstracts International, 46, 2246B.

Crivello, G., Camfield, L., \& Woodhead, M. (2009). How can children tell us about their wellbeing? Exploring the potential of participatory research approaches within young lives. Social Indicators Research, 90, 51-72. DOI 10.1007/s11205-008-9312-x

Connolly, P., Sibbett, C., Hanratty, J., Kerr, K., O'Hare, L., \& Winter, K. (2011). Pupils' Emotional Health and Wellbeing: A Review of Audit Tools and a Survey of Practice in Northern Ireland Post-Primary Schools. Belfast: Centre for Effective Education.

Council for the Curriculum Examinations and Assessment. (2008). Northern Ireland Summary for Schools: End of Key Stage Assessment Outcomes. Retrieved from http://www.rewardinglearning.org.uk/curriculum/key_stages_1_and_2/research_and_statis tics.asp (accessed 1 May 2012).

Department for Children, Schools and Families (2007). Social and emotional aspects of learning for secondary schools. Nottingham: DCSF Publications.

Diener, E. (1994). Assessing subjective wellbeing - Progress and opportunities. Social Indicators Research, 31, 103-157.

DiPerna, J.C., \& Elliot, S.N. (2002). Promoting academic enablers to improve student achievement: An introduction to the mini-series. School Psychology Review, 31(3), 293-297.

Duckworth, A.L., \& Seligman, M.E.P. (2005). Self-discipline outdoes IQ in predicting academic performance of adolsecents. Psychological Science, 16(12), 939-944. DOI: 10.1111/j.1467$9280.2005 .01641 . x$

Durlak, J.A., Weissberg, R.P., Dymnicki, A.B., Taylor, R.D., \& Schellinger, K.B. (2011). The impact of enhancing students' social and emotional learning: A meta-analysis of school- 
based universal interventions. Child Development, 82(1), 405-432. DOI: 10.1111/j.1467-

8624.2010.01564.x

Flay, B., Acock, A., Vuchinich, S., \& Beets, M. (2006). Progress report of the randomized trial of Positive Action in Hawaii: End of third year of intervention. Available from Positive Action, Inc. 264 4th Avenue South, Twin Falls, ID 83301.

Fredrickson, B.L. (2001). The role of positive emotions in positive psychology. American Psychologist, 56(3), 218-226. DOI: 10.1037//0003-066X.56.3.218

Fredrickson, B.L. (1998). What good are positive emotions? Review of General Psychology, 2, 300-319.

Gill, S. (2009). Monitoring and promoting well-being in education - principles and possible approaches to child well-being indicators. Brighton: Guerrand-Hermès Foundation for Peace. Retrieved from http://www.ghfp.org/Portals/0/documents/Gill09_Monitoring_promoting_Wellbeing.pdf (accessed 1 June 2012).

Gutman, L.M., \& Levy, S. (1982). On the definition and varieties of attitude and wellbeing. Social Indicators Research, 10(2), 159-174.

Gutman, L.M., \& Feinstein, L. (2008). Children's well-being in primary school - pupil and school effects: wider benefits of learning: Research Report No.25. London: Centre for Research on the Wider Benefits of Learning, Institute of Education.

Harlen, W. (2004). A Systematic Review of Evidence of the Impact on Students, Teachers and the Curriculum of the Process of Using Assessment by Teachers for Summative Purposes in Research Evidence. London: EPPI-Centre, Social Science Research Unit, Institute of Education.

Harter, S. (1985). Manual for the Self-Perception Profile for Children. Denver, CO: University of Denver. 
Heckman, J.J., Stixrud, J., \& Urzua, S. (2006). The effects of cognitive and noncognitive abilities on labor market outcomes and social behaviour. Journal of Labor Economics, 24(3), 411-482. DOI: 10.1086/504455.

Huebner, E.S. (1991). Initial development of the Students' Life Satisfaction Scale. School Psychology International, 12, 231-240.

Huppert, F., \& Baylis, N. (2004). Well-being: Towards an integration of psychology, neurobiology and social science. Philosophical Transaction of the Royal Society, 359(1449), 1447-1451. DOI: 10.1098/rstb.2004.1520

Laurent, J., Cantanzaro, J., Joiner, T.E., Rudolph, K., Potter, K.I., Lambert, S., et al. (1999). A measure of positive and negative affect for children: Scale development and preliminary validation. Psychological Assessment, 11, 326-338.

Long, J. S., \& Freese, J. (2003). Regression Models for Categorical Dependent Variables Using Stata. Rev. ed. College Station, TX: Stata Press.

Lundy, L., \& McEvoy, L. (2009). Developing outcomes for education services: a children's rights-based approach. Effective Education, 1, 43-60. DOI:10.1080=19415530903044050

Martin, A.J., \& Marsh, H.W. (2006). Academic resilience and its psychological and educational correlates: A construct validity approach. Psychology in the Schools, 43(3), 267281. DOI: $10.1002 /$ pits.20149

Martin, A.J., \& Marsh, H.W. (2008). Academic buoyancy: Towards an understanding of student's everyday resilience. Journal of School Psychology, 46, 53-83. DOI:

10.1016/j.jsp.2007.01.002

Martin, A.J., \& Marsh, H.W. (2009). Academic resilience and academic buoyancy: multidimensional and hierarchical conceptual framing of causes, correlates and cognate constructs. Oxford Review of Education, 35(3), 353-370. DOI: 10.1080/03054980902934639 
Martin, A.J., Colmar, S.H., Davey, L.A., \& Marsh, H.W. (2010). Longitudinal modelling of academic buoyancy and motivation: Do the ' 5 Cs' hold up over time? British Journal of Educational Psychology, 80, 473-496. DOI:10.1348/000709910X486376

Miller, D., Topping, K.J., \& Thurston, A. (2010). Peer tutoring in reading: the effects of role and organization on two dimensions of self-esteem, British Journal of Educational Psychology, 80(30), 417-434.

Morrow, V., \& Mayall, B. (2009). What is wrong with children's well-being in the UK? Questions of meaning and measurement. Journal of Social Welfare \& Family Law, 31(3), 217229. DOI: $10.1080 / 09649060903354522$

Nettle, D. (2005). Happiness - the science behind your smile. Oxford: Oxford University Press.

Northern Ireland Statistics and Research Agency. (2005). Northern Ireland Multiple Deprivation Measure 2005. Belfast: Author.

Nicholson, J.M., Lucas, N., Berthelson, D., \& Wake, M. (2012). Socioeconomic inequality profiles in physical and developmental health from 0-7 years: Australian National Study. Journal of Epidemiology and Community Health, 66, 81-87. DOI: 10.1136/jech.2009.103291

Pell, T., \& Jarvis, T. (2001) Developing attitudes to science scales for use with children of ages from five to eleven years. International Journal of Science Education, 23(8), 847-862.

Pollard, E.L., \& Lee, P.D. (2003). Child well-being: A systematic review of the literature. Social Indicators Research, 61, 59-78.

Saab, H., \& Klinger, D. (2011). School differences in adolescent health and wellbeing: Findings from the Canadian Health Behaviour in School-aged Children study. Social Science and Medicine, 70, 850-858. DOI: 10.1016/j.socscimed.20 09.11.012 
Suldo, S.M., \& Shaffer, E.J. (2008). Looking beyond psychopathology: The dual factor model of mental health in youth. School Psychology Review, 37(1), 52-68.

The KIDSCREEN Group Europe. (2006). The KIDSCREEN Questionnaires - Quality of Life Questionnaires for Children and Adolescents: Handbook. Lengerich: Pabst Science Publishers.

Rosenberg, M. (1965). Society and the adolescent self-image. Princeton, NJ: Princeton University Press.

Rotter, J. (1966). Generalized expectancies for internal versus external control of reinforcements. Psychological Monographs, 80, Whole No. 609.

Ryff, C., \& Keyes, C.L.M. (1995). The Structure of Psychological Well-Being Revisited. Journal of Personality and Social Psychology, 69(4), 719-727.

Sin, N.L., \& Lyubomirsky, S. (2009). Enhancing well-being and alleviating depressive symptoms with positive psychology interventions: A practice-friendly meta-analysis. Journal Of Clinical Psychology: In Session, 65(5), 467-487. DOI: 10.1002/jclp.20593

Wolfe, R.N., \& Johnson, S.D. (1995). Personality as a predictor of college performance. Educational and Psychological Measurement, 55(2), 177-185. DOI: $10.1177 / 0013164495055002002$

Thurston, A., Christie, D., Howe, C.J., Tolmie, A., \& Topping, K.J. (2008). Effects of continuing professional development on group work practices in Scottish primary schools. Journal of InService Education, 34(3), 263 - 282.

Thurston, M., McLeod, J., \& Thurston, A. (2012). Counselling for sight loss: A hermeneutic single case efficacy design study. Counselling Psychology Review, 27, 56-70. 
Lopes, P.N., \& Salovey, P. (2004). Towards a broader education: Social, emotional and practical skills. In J.E. Zins, , R.P. Weissberg, M.C. Wang, \& H.J. Walberg. (Eds.). Building Academic Success on Social and Emotional Learning: What does the Research Say? New York: Teachers College Press. 
Tables

Table 1: Wellbeing outcomes and measure descriptives.

\begin{tabular}{|c|c|c|c|c|c|}
\hline Outcome & Measure & $\begin{array}{l}\text { No. of } \\
\text { items }\end{array}$ & $\begin{array}{l}\text { Min and } \\
\max \\
\text { values }\end{array}$ & $\begin{array}{l}\text { Sample } \\
\text { mean } \\
(\mathrm{SD}) \\
\mathrm{n}\end{array}$ & $\begin{array}{l}\text { Cronbach's } \\
\text { alpha } \\
\text { calculated } \\
\text { for sample }\end{array}$ \\
\hline \multicolumn{6}{|c|}{ Psychological factors } \\
\hline Self esteem & $\begin{array}{l}\text { Harter's (1982) Self } \\
\text { Perception Profile for } \\
\text { Children: Global Self } \\
\text { Worth subscale }\end{array}$ & 6 & 1,4 & $\begin{array}{l}3.21 \\
(0.67) \\
1081\end{array}$ & 0.71 \\
\hline $\begin{array}{l}\text { Psychological } \\
\text { health }\end{array}$ & $\begin{array}{l}\text { KIDSCREEN Psychological } \\
\text { health subscale }\end{array}$ & 7 & $1.6,5$ & $\begin{array}{l}4.15 \\
(0.62) \\
1078\end{array}$ & 0.72 \\
\hline \multicolumn{6}{|c|}{ School engagement factors } \\
\hline $\begin{array}{l}\text { School } \\
\text { environment }\end{array}$ & $\begin{array}{l}\text { KIDSCREEN School } \\
\text { environment subscale }\end{array}$ & 4 & 1,5 & $\begin{array}{l}4.06 \\
(0.84) \\
1077\end{array}$ & 0.74 \\
\hline $\begin{array}{l}\text { Enjoyment of } \\
\text { education }\end{array}$ & $\begin{array}{l}\text { Pell and Jarvis' (2001) } \\
\text { attitudinal scale }\end{array}$ & 9 & $1.2,5$ & $\begin{array}{l}3.87 \\
(0.77) \\
1081\end{array}$ & 0.78 \\
\hline \multicolumn{6}{|c|}{ Family and peer factors } \\
\hline Parent relations & $\begin{array}{l}\text { KIDSCREEN Autonomy } \\
\text { and parent relations } \\
\text { subscale }\end{array}$ & 7 & 1,5 & $\begin{array}{l}3.98 \\
(0.77) \\
1079\end{array}$ & 0.77 \\
\hline $\begin{array}{l}\text { Peer } \\
\text { relationships }\end{array}$ & $\begin{array}{l}\text { KIDSCREEN Peer } \\
\text { relationships subscale }\end{array}$ & 4 & 1,5 & $\begin{array}{l}4.44 \\
(0.72) \\
1075\end{array}$ & 0.77 \\
\hline
\end{tabular}


Table 2: Sample characteristics, by gender and year group.

\begin{tabular}{llll}
\hline Year group & Girls & Boys & Total \\
\hline Year 4 (age 7-8 years) & 244 & 283 & $527(48.8 \%)$ \\
Year 7 (age 10-11 years) & 266 & 288 & $554(51.2 \%)$ \\
\hline Total & $510(47.2 \%)$ & $571(53.8 \%)$ & $1,081(100 \%)$ \\
\hline
\end{tabular}


Table 3: The number of students in the sample achieving each level of the Key Stage standards in English and Math, by gender and year group.

\begin{tabular}{|c|c|c|c|c|c|c|c|}
\hline Gender & Level 1 & Level 2 & Level 3 & Level 4 & Level 5 & Level 6 & Total \\
\hline \multicolumn{8}{|c|}{ Year 4 English Key Stage 1 Results } \\
\hline \multirow[t]{2}{*}{ Girls } & 6 & 113 & 49 & 0 & - & - & 168 \\
\hline & $3.6 \%$ & $67.3 \%$ & $29.2 \%$ & $0 \%$ & & & $100 \%$ \\
\hline \multirow[t]{2}{*}{ Boys } & 10 & 130 & 35 & 0 & - & - & 175 \\
\hline & $5.7 \%$ & $74.3 \%$ & $20 \%$ & $0 \%$ & & & $100 \%$ \\
\hline Sample & 16 & 243 & 84 & 0 & - & - & 343 \\
\hline Total & $4.7 \%$ & $70.8 \%$ & $24.5 \%$ & $0 \%$ & & & $100 \%$ \\
\hline Population & 1422 & 11564 & 8644 & 0 & & & 21630 \\
\hline Total & $6.6 \%$ & $53.5 \%$ & $40.0 \%$ & $0 \%$ & & & $100 \%$ \\
\hline \multicolumn{8}{|c|}{ Year 4 Math Key Stage 1 Results } \\
\hline \multirow[t]{2}{*}{ Girls } & 8 & 105 & 56 & 0 & - & - & 169 \\
\hline & $4.7 \%$ & $62.1 \%$ & $33.1 \%$ & $0 \%$ & & & $100 \%$ \\
\hline \multirow[t]{2}{*}{ Boys } & 7 & 99 & 71 & 0 & - & - & 177 \\
\hline & $4.0 \%$ & $55.9 \%$ & $40.1 \%$ & $0 \%$ & & & $100 \%$ \\
\hline Sample & 15 & 204 & 127 & 0 & - & - & 346 \\
\hline Total & $4.3 \%$ & $60.0 \%$ & $36.7 \%$ & $0 \%$ & & & $100 \%$ \\
\hline Population & 1312 & 10522 & 10166 & 0 & - & - & 22000 \\
\hline Total & $6.0 \%$ & $47.8 \%$ & $46.2 \%$ & $0 \%$ & & & $100 \%$ \\
\hline \multicolumn{8}{|c|}{ Year 7 English Key Stage 2 Results } \\
\hline \multirow[t]{2}{*}{ Girls } & 1 & 4 & 34 & 90 & 49 & 0 & 178 \\
\hline & $.6 \%$ & $2.2 \%$ & $19.1 \%$ & $50.6 \%$ & $27.5 \%$ & $0 \%$ & $100 \%$ \\
\hline \multirow[t]{2}{*}{ Boys } & 4 & 10 & 48 & 89 & 23 & 0 & 174 \\
\hline & $2.3 \%$ & $5.7 \%$ & $27.6 \%$ & $51.1 \%$ & $13.2 \%$ & $0 \%$ & $100 \%$ \\
\hline Sample & 5 & 14 & 82 & 179 & 72 & 0 & 352 \\
\hline Total & $1.4 \%$ & $4.0 \%$ & $23.3 \%$ & $50.9 \%$ & $20.5 \%$ & $0 \%$ & $100 \%$ \\
\hline Population & 110 & 718 & 4455 & 12204 & 6600 & 0 & 24087 \\
\hline Total & $0.5 \%$ & $3.0 \%$ & $18.5 \%$ & $50.7 \%$ & $27.40 \%$ & $0 \%$ & $100 \%$ \\
\hline \multicolumn{8}{|c|}{ Year 7 Math Key Stage 2 Results } \\
\hline \multirow[t]{2}{*}{ Girls } & 0 & 2 & 35 & 79 & 62 & 0 & 178 \\
\hline & $0 \%$ & $1.1 \%$ & $19.7 \%$ & $44.4 \%$ & $34.8 \%$ & $0 \%$ & $100 \%$ \\
\hline \multirow[t]{2}{*}{ Boys } & 1 & 7 & 40 & 73 & 53 & 0 & 174 \\
\hline & $0.6 \%$ & $4.0 \%$ & $23.0 \%$ & $42.0 \%$ & $30.5 \%$ & $0 \%$ & $100 \%$ \\
\hline Sample & 1 & 9 & 75 & 152 & 115 & 0 & 352 \\
\hline Total & $0.3 \%$ & $2.6 \%$ & $21.3 \%$ & $43.2 \%$ & $32.7 \%$ & $0 \%$ & $100 \%$ \\
\hline Population & 114 & 658 & 4068 & 9462 & 9794 & 0 & 24096 \\
\hline Total & $0.5 \%$ & $2.7 \%$ & $16.9 \%$ & $39.8 \%$ & $40.7 \%$ & $0 \%$ & $100 \%$ \\
\hline
\end{tabular}


Table 4: The number of students achieving each level of the composite achievement score, by gender and year group.

\begin{tabular}{cllll}
\hline Composite & \multicolumn{3}{l}{ Year 4} & Year 7 \\
\cline { 2 - 5 } achievement score & Girls & Boys & Girls & Boys \\
\hline 2 & 4 & 4 & 0 & 1 \\
3 & 5 & 8 & 0 & 2 \\
4 & 96 & 89 & 3 & 5 \\
5 & 21 & 42 & 2 & 7 \\
6 & 42 & 32 & 27 & 30 \\
7 & 0 & 0 & 12 & 19 \\
8 & 0 & 0 & 69 & 56 \\
9 & - & - & 19 & 33 \\
10 & - & - & 46 & 21 \\
11 & - & - & 0 & 0 \\
12 & - & - & 0 & 0 \\
\hline Total (by gender) & 168 & 175 & 178 & 174 \\
& $49.0 \%$ & $51.0 \%$ & $50.6 \%$ & $49.4 \%$ \\
Total (by year) & 343 & & 352 & \\
& $100 \%$ & & $100 \%$ & \\
\hline
\end{tabular}


Table 5: Unrotated factor loadings for the six measures of wellbeing.

\begin{tabular}{lc}
\hline Dimension of wellbeing & Factor $1^{*}$ \\
\hline Self esteem & 0.503 \\
Psychological health & 0.648 \\
School environment & 0.676 \\
Enjoyment of education & 0.503 \\
Peer relationships & 0.567 \\
Parent relations & 0.550 \\
\hline
\end{tabular}

* Eigenvalue of Factor $1=2.008$ which explained $33.5 \%$ of the variance. 
Table 6: Parameter estimates of two models predicting wellbeing with gender ${ }^{1}$ and deprivation ${ }^{2}$ as the independent variable, respectively, in each model

\begin{tabular}{lcc}
\hline Predictor variables & \multicolumn{2}{c}{ Parameter estimates (with robust standard errors) } \\
\cline { 2 - 3 } & $3.982(0.28)$ & Model $B^{b}$ \\
\hline Constant $^{b}\left(\beta_{0}\right)$ & $-0.056(0.032)$ & $<0.001(0.057)$ \\
Gender $^{c}\left(\beta_{1}\right)$ & & $-0.101(0.056)$ \\
Deprivation $\left(\beta_{2}\right)$ & & \\
\hline
\end{tabular}

${ }^{a} F(1,27)=3.01, p=.094 ; R^{2}=0.3 \%$

${ }^{\mathrm{b}} \mathrm{F}(1,27)=3.19, \mathrm{p}=0.085, \mathrm{R}^{2}=1.0 \%$

${ }^{c}$ Coded $1=$ boy, $0=$ girl. 
Table 7: Details of the ordinal logistic regression models used in the main analysis to predict achievement

\begin{tabular}{|c|c|c|c|c|}
\hline & \multicolumn{4}{|c|}{ Parameter estimates (logit coefficients with robust standard errors) } \\
\hline & Model 1 & Model 2 & Model 3 & Model 4 \\
\hline Wellbeing $\left(\beta_{1}\right)$ & $-0.056(0.032)$ & $0.475(0.129)$ & $0.477(0.136)$ & $0.281(0.188)$ \\
\hline Year group $\left(\beta_{2}\right)$ & $4.871(0.629)$ & $5.015(0.650)$ & $5.014(0.649)$ & $5.015(0.651)$ \\
\hline $\operatorname{Gender}^{*}\left(\beta_{3}\right)$ & & $-0.244(0.184)$ & $-0.229(1.178)$ & $-0.227(0.190)$ \\
\hline Deprivation $\left(\beta_{4}\right)$ & & $0.003(0.001)$ & $0.003(0.001)$ & $-0.001(0.003)$ \\
\hline Wellbeing $x$ Gender $\left(\beta_{5}\right)$ & & & $-0.004(0.295)$ & \\
\hline Wellbeing $x$ Deprivation $\left(\beta_{6}\right)$ & & & & $0.001(0.001)$ \\
\hline Log pseudolikelihood & -1012.938 & -986.202 & -986.202 & -985.622 \\
\hline McFadden's $R^{2}$ & 0.234 & 0.254 & 0.254 & 0.255 \\
\hline
\end{tabular}

* Coded 1=boy, 0=gir. 